\title{
A narrative review of modern approach and outcomes evaluation in congenital heart defects
}

\author{
Antonio F. Corno ${ }^{1}$, Damien J. LaPar ${ }^{1}$, Wen Li $^{2}$, Jorge D. Salazar ${ }^{1}$ \\ ${ }^{1}$ Pediatric and Congenital Cardiac Surgery, Houston Children's Heart Institute, Memorial Hermann Children's Hospital, University of Texas Health, \\ McGovern Medical School, Houston, Texas, USA; ${ }^{2}$ Division of Clinical and Translational Sciences, Department of Internal Medicine, University of \\ Texas Health, McGovern Medical School, Houston, Texas, USA \\ Contributions: (I) Conception and design: AF Corno, DJ LaPar, JD Salazar; (II) Administrative support: AF Corno, DJ LaPar; (III) Provision of study \\ and materials: AF Corno; (IV) Collection and assembly of data: AF Corno; (V) Data analysis and interpretation: All authors; (VI) Manuscript writing: \\ All authors; (VII) Final approval of manuscript: All authors. \\ Correspondence to: Antonio F. Corno, MD, FRCS, FETCS, FACC. Pediatric and Congenital Cardiac Surgery, Houston Children's Heart Institute, \\ Hermann Children's Hospital, University of Texas Health, McGovern Medical School, 6410 Fannin Street, UTPB Suite 425.20, Houston, Texas, \\ 77030, USA. Email: antonio.f.corno@uth.tmc.edu.
}

Objective: The purpose of this review is to highlight critical advances and innovative approaches to the most challenging clinical situations in congenital heart surgery, to establish a new perspective from which to evaluate current clinical practice patterns and contemporary United States program ranking systems.

Background: The past decades have witnessed substantial advances in the treatment of congenital heart defects. New strategies are deeply rooted in calculated risk-taking innovations. Pioneer surgeons developed, improved and refined critical operative skills and techniques to optimize cardiovascular physiology, decrease operative mortality and improve clinical outcomes.

Methods: Unfortunately, in the modern surgical era, supportive environments to allow surgeons to make similar gains and innovative contributions remain scarce. In the current practice, overall procedure volume is prioritized to safeguard quality metrics, including hospital survival and length of stay, surgical complications, and neurocognitive outcomes. As a result, exceptional surgical results have become translated and defined by public ranking systems such as the US News and World Report Best Children's Hospital National Ranking (USNWR) and the Congenital Heart Surgery Database of the Society for Thoracic Surgeons (CHSD-STS), primary based upon early post-operative mortality. This reality places surgeons in a vulnerable position where pressure to achieve a high clinical ranking contrasts with a surgeon definition of "acceptable" surgical risk. Currently, the most frequently used risk stratification tools do not factor in important differences in strategies, such as staged palliation versus complete repair, or bi-ventricular versus uni-ventricular physiology. This favors hospitals pursuing multistage surgical approaches, even if the result is worse long-term morbidity, mortality and increased resource utilization. This economy of ranking-based decision-making causes surgeons either avoid operating altogether or accept less advantageous multi-staged treatment strategies for patients with elevated expected mortality. Such an environment also might present much farther-reaching negative impacts on the growth and development of junior surgeons and trainees, as well as on the pursuit of new surgical innovations to aid future generations of patients.

Conclusions: Risk aversive surgical behavior is creating an environment not favorable for the children born with truly complex congenital heart defects.

Keywords: Biventricular conversion; congenital heart surgery; multidisciplinary approach; risk-stratification; surgical outcomes

Submitted Apr 13, 2021. Accepted for publication Jul 23, 2021.

doi: $10.21037 / \mathrm{tp}-21-163$

View this article at: https://dx.doi.org/10.21037/tp-21-163 


\section{Introduction}

Undoubtedly, the past few decades have witnessed substantial advances in the treatment of congenital heart defects. Many of the most significant advances in surgical treatment strategies and improved outcomes are deeply rooted in and dependent upon well-educated and calculated risk-taking innovations. In former surgical eras when the risk of doing nothing for congenital heart defects was unacceptable, pioneering children, families and surgeons, were willing to undertake and accept the substantial risks of innovative congenital heart surgery (1). Through the process of daring greatly, pioneer surgeons such as Robert E. Gross, Alfred Blalock, John H. Gibbon, Walton C. Lillehei, Brian G. Barrat-Boyes, John W. Kirklin, GianCarlo Rastelli, Dwight C. McGoon, Donald N. Ross, Francis Fontan, Paul A. Ebert, Leonard L. Bailey, Ake Senning, William T. Mustard, Adib D. Jatene, Yves Lecompte, Marc R. deLeval, Aldo R. Castaneda, William I. Norwood, just to name few of them, developed, improved and refined critical operative skills and techniques to better optimize cardiovascular physiology, decrease operative mortality and improve clinical outcomes (1). Unfortunately, in the modern surgical era, supportive environments to allow surgeons and caregivers to make similar gains and innovative contributions to the field remain scarce. In the current practice environment for many congenital heart programs, overall procedure volume is often prioritized in an attempt to safeguard quality metrics, including, but not limited to, hospital survival, hospital length of stay, surgical complications, and neurocognitive outcomes (2). As a result, exceptional surgical results have become translated and defined by various public reporting and ranking systems such as the US News and World Report Best Children's Hospital National Ranking (USNWR) (1). This reality has placed surgeons and hospitals in a vulnerable position where pressure to achieve a high clinical ranking may contrast with a surgeon or hospitals definition of "acceptable" surgical risk. Further challenging this position are currently available for risk stratification used by both the USNWR and by the Congenital Heart Surgery Database of the Society for Thoracic Surgeons (CHSD-STS), that remain primary based upon on early post-operative mortality. Currently, the most frequently used risk stratification tools do not factor in important differences in strategies of surgical management, such as staged palliation versus complete repair, or biventricular versus uni-ventricular physiology, that favors hospitals pursuing multistage surgical approaches, even if the result is worse long-term morbidity, mortality and increased resource utilization (3). This result of economy of ranking-based decision-making is that surgeons and/or hospitals either avoid operating altogether or accept less advantageous multi-staged treatment strategies for infants and children who may present with elevated expected mortality (2). Such an environment also presents fartherreaching negative impacts on the growth and development of junior surgeons and trainees, allowed to perform surgery only in the most straightforward cases, as well as on the pursuit of new surgical innovations to aid future generations of patients (1). Thus, risk aversive surgical behavior, combined with an increasing rate of premature births and associated elevated surgical risk, is creating an environment not favorable for the children born with truly complex congenital heart defects.

The purpose of this review is to highlight critical advances and innovative approaches to the most challenging clinical situations made in congenital heart surgery, to establish a historical perspective from which to evaluate current clinical practice patterns and contemporary United States program ranking systems.

We present the following article in accordance with the Narrative Review reporting checklist (available at https:// dx.doi.org/10.21037/tp-21-163).

\section{Review methods}

Over the past several decades, the management of congenital heart defects has seen substantial progress and improved treatment outcomes, with a significant reduction in hospital mortality and an increased attention by caregivers to patient and family quality of life. Advances in patient outcomes have been achieved due to expanding knowledge gained by multidisciplinary collaborations amongst clinic and basic/translational science researchers, biologists, mathematicians, bioengineers, and experts of imaging and neurodevelopmental issues. Thus, the medical and surgical fields dedicated to the treatment of congenital heart disease are poised to examine the expanding horizons of a rapidly evolving field.

The materials utilized for this review originated from a MedLine search, together with the specific search in the journals covering the field of congenital heart surgery: Fournal of Thoracic and Cardiovascular Surgery, Annals of Thoracic Surgery, European Fournal of Cardio-Thoracic Surgery, Seminar of Thoracic Cardiovascular Surgery, Pediatric Cardiology, Cardiology in the Young, World fournal of Pediatric 
and Congenital Heart Surgery. The information on the rankings have been obtained from the US News and World Report Best Children's Hospital National Ranking (USNWR) and from the Congenital Heart Surgery Database of the Society for Thoracic Surgeons (CHSDSTS).

Major scientific contributions have emerged from both basic science research and clinical pathways related to prenatal diagnosis of congenital heart defects and as well as long-term clinical follow-up. In fact, basic science research studies have provided better knowledge on the heart morphology and function (4-6) and have explored potential techniques to further increase the myocardial performance (7-9). Important experimental and clinical studies have also focused to reduce the neurological and cardio-circulatory damages occurring during the fetal life in the presence of congenital heart defects (10-13). These efforts have resulted in reliable approaches to prenatal diagnosis in order to allow for the coordinated delivery of babies with congenital heart defects in close connection to tertiary referral centers equipped with appropriate neonatal interventional critical care $(14,15)$.

Over the past decade, our field has also seen significant advances in the quality of post-natal diagnosis. Technological advances in post-natal imaging has been dramatically improved by the introduction of threedimensional echocardiography $(16,17)$, by accurate anatomic definition of congenital heart defects lesions through low radiation dose computed tomography (18-20), and by the functional assessment of flows and myocardial function with magnetic resonance imaging $(21,22)$. Modern imaging techniques have also allowed for more precise clinical decision-making and planning related to the performance of interventional catheter-based procedures as well as for surgical repair through enhanced imaging techniques with segmentation of the heart structures to facilitate three-dimensional rendering or printing of complex heart anatomy $(23,24)$.

Perioperative management has also undergone substantial changes related to the conduct of anesthesia and intraoperative cardiopulmonary bypass (25-27), as well as approaches to myocardial protection with improved cardioplegia (28-30). The importance of precise general anesthesia, proper mechanical ventilation, anticoagulation and blood products management, as well as cardiopulmonary bypass strategies have allowed physicians and surgeons to pursue more aggressive treatment strategies with safety and confidence. Cardiopulmonary bypass strategies have evolved with optimization of priming of the circuit, proper conduction of flow, pressure, and temperature, avoidance of myocardial distension, and accurate weaning strategies. As a result, it is now possible to dedicate focused surgical attention to all morphological details without the pressure of time constraints in order to provide complete surgical repairs for most congenital heart defects lesions. Immediate assessment of surgical results has been provided by improved intra-operative surface and/or transesophageal echocardiography before and after the procedure $(31,32)$. Furthermore, significant advances in perioperative support to critically ill infants and children with congenital heart defects have been achieved with readily available and improved extracorporeal membrane oxygenation techniques. Expanded knowledge of extracorporeal membrane oxygenation indications and timing, cannulations strategies, anticoagulation management, extracorporeal membrane oxygenation circuit assessment and optimal flow rates have allowed clinicians to provide improved cardio-circulatory support and mitigate patient complications (33-35).

An increasing emphasis and attention to the dynamic early post-operative period has become apparent in recent years. Critical in this period is the process of patient transport from the operative room to the intensive care unit, the continuous monitoring and stability of all vital and laboratory parameters, appropriate oxygen delivery, maintenance of homeostasis and cardiac function, fluid balance, and adequate ventilatory and pharmacological support $(36,37)$. During the entire post-operative period, patients are typically managed to achieve a minimum hematocrit close to $40 \%$ as oxygen delivery is equal to cardiac output X oxygen saturation X hematocrit. Among cardiac neonates and infants, particularly when cardiac output has yet to normalize and the oxygen saturation is low if the systemic and pulmonary circulations have not yet been completely separated, the only way to improve the oxygen delivery is to increase the hematocrit. Finally the importance of washing blood products to eliminate byproducts has become essential prior to transfusing an infant, either in operating room as well as in the immediate post-operative period.

From a surgical perspective, all the aforementioned advances in prenatal assessment, imaging technology, and perioperative support, have allowed for more aggressive approaches to the surgical treatment of congenital heart defects with improved safety and confidence. More specifically, surgeons have become positioned to evaluate 
complex surgical reconstructions from a different vantage point related to not only the timing of surgery by also to type of surgical approach. One example is that the trend for primary surgical reconstruction to occur during the neonatal period or during early infancy has become more widely accepted within the congenital cardiac surgical community. Early complete repair presents the major advantage of reducing the exposure of the body of the patients to long periods with the damaging effects of hypoxemia, poor perfusion, pulmonary hypertension, heart failure, potentially causing long-term negative consequences (38).

Another example is the accumulated knowledge of the deleterious effects of the Fontan circulation, causing irreversible lesions in an alarming percentage of adolescents and young adults $(39,40)$. This understanding has served to promote the investigation of all possible ways to avoid surgical palliation to the Fontan circulation with an increasing emphasis at our center to pursue a bi-ventricular circulation whenever possible. We believe that significant advances in patient quality of life exist with the avoidance and/or conversion of uni-ventricular to bi-ventricular circulation.

At our center, a bi-ventricular circulation remains the objective for every child when possible. Pre-operatively, the decision between uni-ventricular and bi-ventricular surgical approach has been enormously enhanced by careful and dedicated preoperative imaging. The use of advanced echocardiographic imaging, cardiac tomography, magnetic resonance imaging, and three-dimensional reconstructions to provide accurate pre-operative measurements of intracardiac anatomy, including the size and morphology of inflow and outflow tracts of both ventricles as well as ventricular volumes, has become indispensable in preoperative surgical planning for complex repairs (41).

This concept of staged surgical approach for a biventricular circulation is not new: Paul Ebert already proposed the "staged partitioning" of single ventricle on 1984 (42), Roxane McKay the "staged septation" of double inlet left ventricle on 1986 (43), and Jan Quaegebeur and colleagues revised the surgical technique on 2022, to avoid the Fontan pathway (44).

The pathway towards a bi-ventricular circulation is taken into consideration for all patients referred in the newborn period, by appropriate staging of the surgical procedures. For patients referred at any subsequent steps towards a univentricular pathway, after Norwood, bidirectional Glenn or Fontan completion, the possibility for a bi-ventricular conversion is ruled out only after all investigations have denied this surgical option (45-53).

\section{Ranking}

The expanding horizon for the management of congenital heart defects remains exciting, but it must be pursued in the context of patient safely and sustainability. These approaches can only be validated by rigorous assessment of surgical outcomes evaluated against appropriate patient risk stratification.

Table 1 reports data from the March 2021 report of the CHDB-STS, related to the period from 2015 to 2018. Analysis of these data was limited to hospitals reporting a high volume of high-risk patients, defined by those centers reporting more than 150 cases of STAT group 4 and more than 30 cases of STAT group 5. Hospitals are ranked in descending order by expected mortality risk.

A statistical analysis has been conducted (WL) on these data, with hospital mortality and expected mortality, based on risk stratification with the STAT groups. The proportion of high-risk cases could predict the hospital mortality $(\mathrm{P}=0.07)$. Each one percent increase in the proportion of STAT 5 cases elevated the observed hospital mortality by $0.28 \%$ (95 confidence interval: $0.01-0.47 \%$ ). With a $95 \%$ confidence level the observed mortality in our center was significantly lower than the expected mortality: observed mortality $(\%)=2.9,95 \%$ confidence interval: $1.9-4.3$, $(\mathrm{P}=0.01)$.

The data reported in Table 1, as well as their statistical analysis, clearly demonstrate the evident discrepancies between the rankings produced from the US News and World Report Best Children's Hospital National Ranking (USNWR) and from the Congenital Heart Surgery Database of the Society for Thoracic Surgeons (CHSDSTS). The hospitals with high score in the ranking available to the public (USNWR), are characterized for high volume of cases, but low risk stratification, and low percentages of high-risk patients (STAT 4 and 5), while hospitals accepting large percentages of high-risk patients, and with high risk stratification, do not even appear in the first positions of the ranking offered to the public. In our opinion the public is offered misleading information, because the data provided from the media are only limited to the total number of cases, therefore to the quantity, without any data on the quality, related to the difficulty and complexity of the cases accepted for surgery, and the outcomes provided in the most complex patients. 
Table 1 Expected mortality, based on risk stratification, and observed mortality, reported by the Society for Thoracic Surgeons (STS) congenital data-base, with incidence of STAT 4 and 5 patients and US News and World Report Best Children's Hospital National Ranking (USNWR) ranking

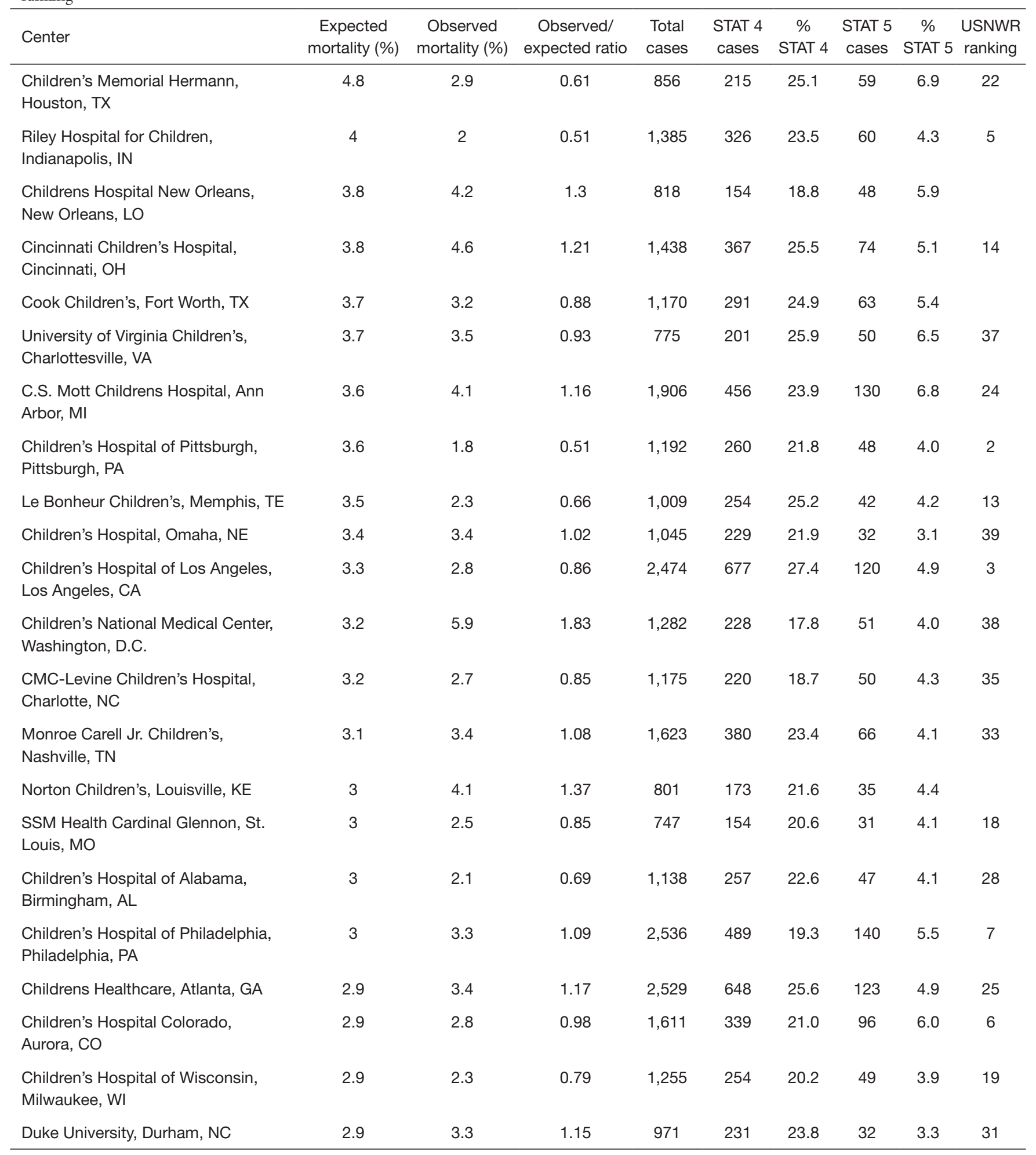

Table 1 (continued) 
Table 1 (continued)

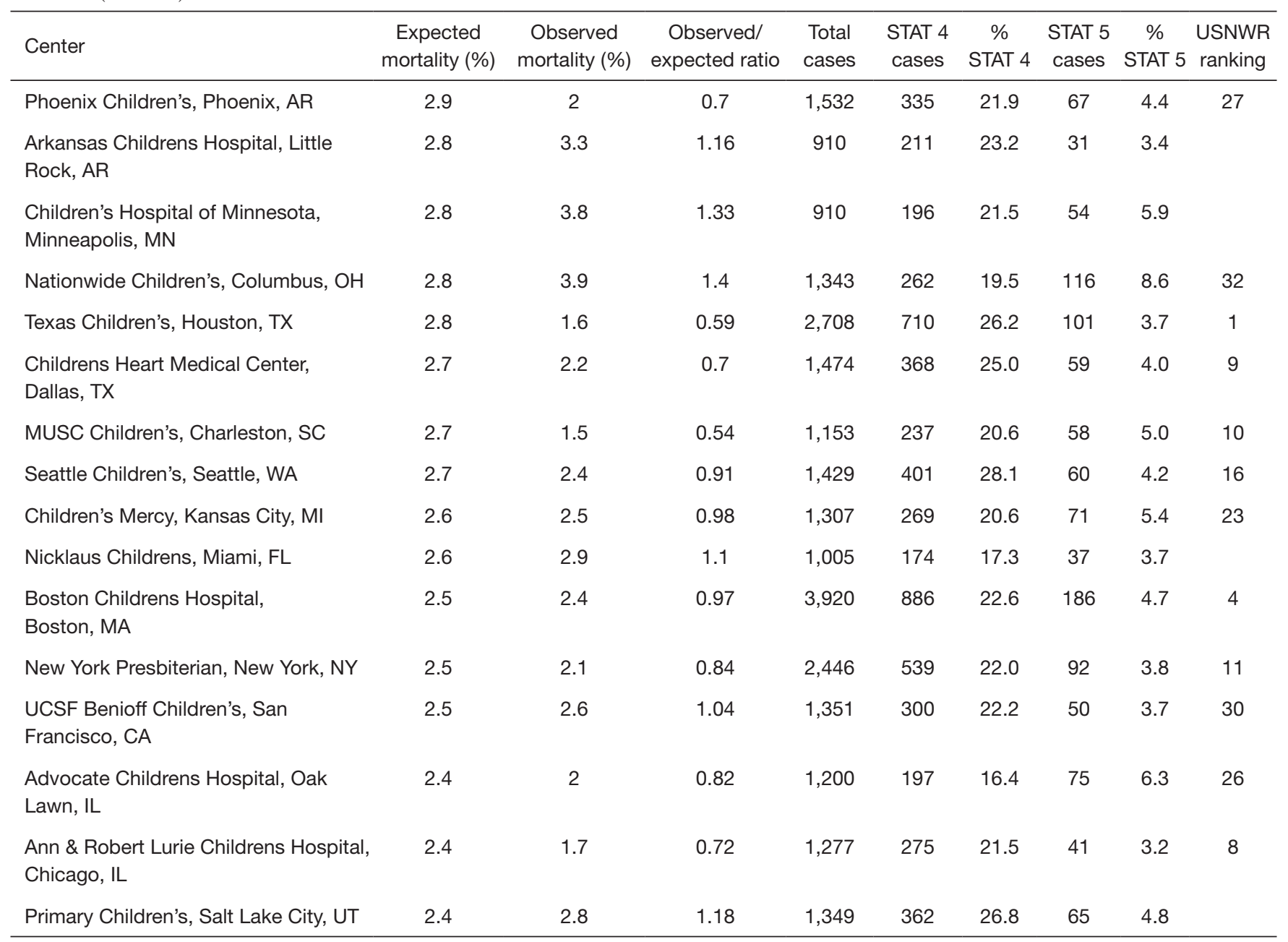

\section{Conclusions}

The past several decades have witnessed substantial surgical advances in the care of children with congenital heart defects through the pioneering efforts of innovative and daring surgeons. Undoubtedly, such progress has been facilitated by supportive hospital and surgical environments that allow the surgical management of children with very complex congenital heart defects by offering them the most advanced techniques, including an emphasis on biventricular repair/conversion and avoiding the pathway of uni-ventricular repair whenever possible. Currently available publicly reported data reveal significant variation in hospital case mix related to the performance of high-risk operations. There does not appear to be a strong correlation between the ranking scores available to the public and performance of high-risk congenital heart operations, despite center performance. These data must be carefully evaluated, to avoid surgeon and hospital decision making based on risk aversion, and they argue for the establishment of identified centers of excellence for the performance of the most complex congenital heart operations based upon center performance.

\section{Acknowledgments}

Funding: None.

\section{Footnote}

Reporting Checklist: The authors have completed the Narrative Review reporting checklist. Available at https:// 
dx.doi.org/10.21037/tp-21-163

Peer Review File: Available at https://dx.doi.org/10.21037/ tp-21-163

Conflicts of Interest: All authors have completed the ICMJE uniform disclosure form (available at https://dx.doi. org/10.21037/tp-21-163). AFC serves as an unpaid editorial board member of Translational Pediatrics from Apr 2020 to Mar 2022. The other authors have no conflicts of interest to declare.

Ethical Statement: The authors are accountable for all aspects of the work in ensuring that questions related to the accuracy or integrity of any part of the work are appropriately investigated and resolved.

Open Access Statement: This is an Open Access article distributed in accordance with the Creative Commons Attribution-NonCommercial-NoDerivs 4.0 International License (CC BY-NC-ND 4.0), which permits the noncommercial replication and distribution of the article with the strict proviso that no changes or edits are made and the original work is properly cited (including links to both the formal publication through the relevant DOI and the license). See: https://creativecommons.org/licenses/by-nc-nd/4.0/.

\section{References}

1. Collins RT 2nd, Shin AY, Hanley FL. Sacrificing the Future for the Sake of the Present. Ann Surg 2020;271:225-6.

2. Spray TL, Gaynor JW. A Word of Caution in Public Reporting. Semin Thorac Cardiovasc Surg Pediatr Card Surg Annu 2017;20:49-55.

3. Jonas RA. WJPCHS Presidential Address: Threats to the Continuing Globalization of Early Primary Repair. World J Pediatr Congenit Heart Surg 2019;10:58-65.

4. Piersanti R, Africa PC, Fedele M, et al. Modeling cardiac muscle fibers in ventricular and atrial electrophysiology simulations. Comput Methods Appl Mech Engineer 2021;373:113468.

5. Di Gregorio S, Fedele M, Pontone G, et al. A computational model applied to myocardial perfusion in the human heart: from large coronaries to microvasculature. J Comput Physics 2021;424:109836.

6. Fedele M, Quarteroni A. Polygonal surface processing and mesh generation tools for the numerical simulation of the cardiac function. Int J Numer Method Biomed Eng 2021;37:e3435.

7. Ishigami S, Sano T, Krishnapura S, et al. An overview of stem cell therapy for paediatric heart failure. Eur J Cardiothorac Surg 2020;58:881-7.

8. Vincenti M, O'Leary PW, Qureshi MY, et al. Clinical Impact of Autologous Cell Therapy on Hypoplastic Left Heart Syndrome After Bidirectional Cavopulmonary Anastomosis. Semin Thorac Cardiovasc Surg 2020. [Epub ahead of print]. doi: 10.1053/j.semtcvs.2020.11.002.

9. Guariento A, Doulamis IP, Duignan T, et al. Mitochondrial transplantation for myocardial protection in ex-situ-perfused hearts donated after circulatory death. J Heart Lung Transplant 2020. [Epub ahead of print]. doi: 10.1016/j.healun.2020.06.023.

10. Rychik J, Goff D, McKay E, et al. Characterization of the Placenta in the Newborn with Congenital Heart Disease: Distinctions Based on Type of Cardiac Malformation. Pediatr Cardiol 2018;39:1165-71.

11. Hawkins KE, Corcelli M, Dowding K, et al. Embryonic Stem Cell-Derived Mesenchymal Stem Cells (MSCs) Have a Superior Neuroprotective Capacity Over Fetal MSCs in the Hypoxic-Ischemic Mouse Brain. Stem Cells Transl Med 2018;7:439-49.

12. Claessens NHP, Chau V, de Vries LS, et al. Brain Injury in Infants with Critical Congenital Heart Disease: Insights from Two Clinical Cohorts with Different Practice Approaches. J Pediatr 2019;215:75-82.e2.

13. Lee FT, Marini D, Seed M, Sun L. Maternal hyperoxygenation in congenital heart disease. Transl Pediatr 2021;10(8):1-0. doi: 10.21037/tp-20-226

14. Sun HY. Prenatal diagnosis of congenital heart defects: echocardiography. Transl Pediatr 2021;10(8):1-0. doi: 10.21037/tp-20-164

15. Bonnet D. Impacts of prenatal diagnosis of congenital heart diseases on outcomes. Transl Pediatr 2021;10(8):1-0. doi: $10.21037 / \mathrm{tp}-20-267$

16. Cantinotti M, Giordano R, Koestenberger M, et al. Echocardiographic examination of mitral valve abnormalities in the paediatric population: current practices. Cardiol Young 2020;30:1-11.

17. Moura-Ferreira S, Sampaio F, Ribeiro J, et al. A rare case series of mitral valve clefts diagnosed by $3 \mathrm{D}$ echocardiography and mini-review of the literature. Echocardiography 2019;36:1203-7.

18. Priya S, Nagpal P, Sharma A, et al. Imaging Spectrum of Double-Outlet Right Ventricle on Multislice Computed Tomography. J Thorac Imaging 2019;34:W89-99. 
19. Cheasty E, Mahboobani S, Rubens M, et al. The use of cardiovascular CT for the follow up of paediatric hypoplastic left heart syndrome. J Cardiovasc Comput Tomogr 2020;14:e18-9.

20. Dodge-Khatami J, Adebo DA. Evaluation of complex congenital heart disease in infants using low dose cardiac computed tomography. Int J Cardiovasc Imaging 2021;37:1455-60.

21. Muthurangu V. Cardiovascular Magnetic Resonance in Congenital Heart Disease: Focus on Heart Failure. Heart Fail Clin 2021;17:157-65.

22. Karimi-Bidhendi S, Arafati A, Cheng AL, et al. Fully-automated deep-learning segmentation of pediatric cardiovascular magnetic resonance of patients with complex congenital heart diseases. J Cardiovasc Magn Reson 2020;22:80.

23. Averkin II, Grehov EV, Pervunina TM, et al. $3 \mathrm{D}$-printing in preoperative planning in neonates with complex congenital heart defects. J Matern Fetal Neonatal Med 2020. [Epub ahead of print]. doi: 10.1080/14767058.2020.1771691.

24. Van Arsdell GS, Hussein N, Yoo SJ. Three-dimensional printing in congenital cardiac surgery-Now and the future. J Thorac Cardiovasc Surg 2020;160:515-9.

25. Corno AF, Bostock C, Chiles SD, et al. Comparison of Early Outcomes for Normothermic and Hypothermic Cardiopulmonary Bypass in Children Undergoing Congenital Heart Surgery. Front Pediatr 2018;6:219.

26. Harris AD, Hubbard RM, Sam RM, et al. A Retrospective Analysis of the Use of 3-Factor Prothrombin Complex Concentrates for Refractory Bleeding After Cardiopulmonary Bypass in Children Undergoing Heart Surgery: A Matched Case-Control Study. Semin Cardiothorac Vasc Anesth 2020;24:227-31.

27. Gautam NK, Pierre J, Edmonds K, et al. Transfusing Platelets During Bypass Rewarming in Neonates Improves Postoperative Outcomes: A Randomized Controlled Trial. World J Pediatr Congenit Heart Surg 2020;11:71-6.

28. Durandy Y. Pediatric myocardial protection. Curr Opin Cardiol 2008;23:85-90.

29. Matte GS, del Nido PJ. History and use of del Nido cardioplegia solution at Boston Children's Hospital. J Extra Corpor Technol 2012;44:98-103.

30. Luongo TS, Lambert JP, Gross $\mathrm{P}$, et al. The mitochondrial $\mathrm{Na}+\mathrm{Ca} 2+$ exchanger is essential for $\mathrm{Ca} 2+$ homeostasis and viability. Nature 2017;545:93-7.

31. Stern KWD, Emani SM, Peek GJ, et al. Epicardial Echocardiography in Pediatric and Congenital Heart
Surgery. World J Pediatr Congenit Heart Surg 2019;10:343-50.

32. Pavithran S, Natarajan K, Vishwambaran B, et al. Preliminary evaluation of a microtransesophageal probe in neonates and young infants undergoing surgery for congenital heart disease. Ann Pediatr Cardiol 2014;7:173-9.

33. Corno AF, Faulkner GM, Harvey C. Extra-Corporeal Membrane Oxygenation for Neonatal Respiratory Support. Semin Thorac Cardiovasc Surg 2020;32:553-9.

34. Corno AF, Faulkner GM, Harvey C. Mobile ExtraCorporeal Membrane Oxygenation. ASAIO J 2021;67:594-600.

35. Wu Y, Zhao T, Li Y, et al. Use of Extracorporeal Membrane Oxygenation After Congenital Heart Disease Repair: A Systematic Review and Meta-Analysis. Front Cardiovasc Med 2020;7:583289.

36. Klee P, Arni D, Saudan S, et al. Ketosis After Cardiopulmonary Bypass in Children Is Associated With an Inadequate Balance Between Oxygen Transport and Consumption. Pediatr Crit Care Med 2016;17:852-9.

37. Weigl M, Heinrich M, Keil J, et al. Team performance during postsurgical patient handovers in paediatric care. Eur J Pediatr 2020;179:587-96.

38. Sun Y, Jiang C, Hong H, et al. Effects of hypoxia on cardiomyocyte proliferation and association with stage of development. Biomed Pharmacother 2019;118:109391.

39. Gewillig M, Brown SC. The Fontan circulation after 45 years: update in physiology. Heart 2016;102:1081-6.

40. Claessen G, La Gerche A, Van De Bruaene A, et al. Heart Rate Reserve in Fontan Patients: Chronotropic Incompetence or Hemodynamic Limitation? J Am Heart Assoc 2019;8:e012008.

41. Corno AF, Durairaj S, Skinner GJ. Narrative review of assessing the surgical options for double outlet right ventricle. Transl Pediatr 2021;10:165-76.

42. Ebert PA. Staged partitioning of single ventricle. J Thorac Cardiovasc Surg 1984;88:908-13.

43. McKay R, Bini RM, Wright JP. Staged septation of double inlet left ventricle. Br Heart J 1986;56:563-6.

44. Margossian RE, Solowiejczyk D, Bourlon F, et al. Septation of the single ventricle: revisited. J Thorac Cardiovasc Surg 2002;124:442-7.

45. Bacha E. Borderline left ventricle: Trying to see the forest for the trees. J Thorac Cardiovasc Surg 2017;154:570-1.

46. Chen Q, Li S, Hua Z, et al. Anatomical Repair Conversion After Bidirectional Cavopulmonary Shunt for Complex Cardiac Anomalies: Palliation is Not a One-Way Path. 
Pediatr Cardiol 2018;39:604-9.

47. Oladunjoye OO, Piekarski B, Banka P, et al. Staged ventricular recruitment in patients with borderline ventricles and large ventricular septal defects. J Thorac Cardiovasc Surg 2018;156:254-64.

48. Andersen ND, Scherba JC, Turek JW. Biventricular Conversion in the Borderline Hypoplastic Heart. Curr Cardiol Rep 2020;22:115.

49. Haberer K, Fruitman D, Power A, et al. The hypoplastic left heart complex: fetal predictors of growth and surgical repair. Ultrasound Obstet Gynecol 2020. [Epub ahead of print]. doi: 10.1002/uog.23558.

50. Houeijeh A, Godart F, Pagniez J, et al. From Fontan

Cite this article as: Corno AF, LaPar DJ, Li W, Salazar JD. A narrative review of modern approach and outcomes evaluation in congenital heart defects. Transl Pediatr 2021;10(8):21142122. doi: $10.21037 / \mathrm{tp}-21-163$ to Anatomical Repair 16 Years Later. Ann Thorac Surg 2021;111:e15-7.

51. Sunil GS, Srimurugan B, Kottayil BP, et al. Conversion of prior univentricular repairs to septated circulation: Case selection, challenges, and outcomes. Indian J Thorac Cardiovasc Surg 2021;37:91-103.

52. Sojak V, Bokenkamp R, Kuipers I, et al. Left heart growth and biventricular repair after hybrid palliation. Interact Cardiovasc Thorac Surg 2021;32:792-9.

53. Zheng WC, Lee MGY, d'Udekem Y. Fate of patients with single ventricles who do not undergo the Fontan procedure. Ann Thorac Surg 2021. [Epub ahead of print]. doi: 10.1016/j.athoracsur.2021.02.011. 